\title{
Rules and Exemptions: The Politics of Difference Within Liberalism
}

\author{
Maria Paola Ferretti · Lenka Strnadová
}

Published online: 3 September 2009

(C) Springer Science+Business Media B.V. 2009

\section{Introduction}

\section{Liberalism and Difference}

In what ways might we best, and justly, allow for cohabitation between individuals and groups with plural conceptions of the good? Confronting this question, students of political philosophy in the past two decades have encountered a routine contrast between liberal universalism, with a focus on equal individual rights and uniform application of the law, and on the other hand various versions of a "politics of difference'. The simplest statement of the first view would be that the law should apply to all, irrespective of divergences in culture, religious belief, or ethical orientation. For the second approach, the law should somehow accommodate or recognise such divergences-for example, through the granting of group rights. So one crucial set of questions at stake in such debates concerns whether the law should accommodate such differences; another is how it should do so. A series of important, widely discussed texts (Young 1990; Kymlicka 1995; Parekh 2000; Barry 2001) have tackled such issues-with the issues themselves, for better or worse, becoming a core and staple part of what contemporary political philosophy is about. And given the pre-eminence of liberalism within that field, much of the discussion has centred on whether liberal approaches accommodate, or run counter to, due attention to the social and political significance of difference.

M. P. Ferretti $(\bowtie)$

Centre for European Law and Politics (ZERP), University of Bremen, Universitätsallee GW1, 28358 Bremen, Germany

e-mail: ferretti@zerp.uni-bremen.de; mariapaolaf@yahoo.co.uk

L. Strnadová

Department of Politics and International Studies, University of West Bohemia in Pilsen, Sedláčkova 15, 30100 Plzeň, Czech Republic

e-mail: 1strnad@kap.zcu.cz 
As these debates have unfolded, so the contrast between liberals and their opponents has tended to become less pronounced than the simple classroom contrast might suggest. Thus in response to communitarian and other lines of critique, various liberal theorists have engaged with the discussion and justification of possible instruments for the protection of cultural identity, including selfdetermination rights, rights to guaranteed political representation, rights to subsidy and support, or rights to be exempt from generally applicable laws (Kymlicka 1995; pp. 26-33). The articles in this volume are concerned with the latter claim, exploring the arguments for and against a 'rule and exemption' approach by engaging from different perspectives with various problems linked to its application and justification.

\section{The 'Rule and Exemption’ Approach}

The so-called 'rule and exemption' approach to citizens' demands for differential treatment aims at combining respect for general legal obligations and attention to specific minority issues. Rather than repealing or changing the law in order to accommodate ethical differences, some governments with growing confidence have adopted 'the approach that keeps the rule that is objected to for most of the population but allows members of cultural or religious minorities to opt out of the obligation to obey it' (Barry 2001, p. 33). This is taken to apply where minority claims and complaints do not target the political and legal order as a whole, but only specific laws or rules-challenged on the basis that they place on some citizens an unfair burden. This burden arises from the conflict between the general rule on the one hand and the particularities of conscience or religious obligation on the part of some citizens.

In Europe, traditionally, requests for exemptions have been treated as a matter of freedom of conscience. Cases of conscientious objection arise when the freedom to carry out one's moral duty comes into conflict with widely accepted positive laws. Paradigmatic in this sense is the case of the conscientious objection to compulsory military service, which is recognised as a lawful option (objection secundum legem) in most European countries. Note however that conscientious objection against the law (contra legem) represent a different case, in which the objector accepts that her act contravenes the law, and faces punishment for not complying. In this sense conscientious objection is a form of contestation of a universal law on the part of some individuals, rather than being a lawful option foreseen as an exemption to a general rule, as is the case with conscientious objection secundum legem.

In some countries, such as the USA, Canada, and the UK, claims for exemption have been made by various religious or ethic groups, in cases in which a 'neutral' law unintentionally prohibits or compels a practice with a distinctive significance for members of a certain cultural or religious group. An oft-discussed example is that of the obligation to wear a protective helmet when riding motorcycles, which, although intended to make driving safer, clashes with the religious obligation for Sikh men to wear the traditional turban (White 2007, p. 133). Exemptions from the obligation to wear a safety helmet for Indian Sikhs have been recognised in various countries, including the UK. Exemption rights are presented by some as 
'individually exercised negative liberties granted to members of a religious or cultural group whose practices are such that a generally and ostensibly neutral law would be a distinctive burden to them' (Levy 1997, p. 25). Other examples include, in certain territories, the granting of a licence to hunt and fish, or to slaughter animals in a particular way, exclusively to certain ethnic groups so as to preserve their traditional way of life. Others still concern dress codes, schooling obligations and health care requirements. According to this understanding, there are practices that have a very special meaning for members of certain groups that they do not have for the majority culture, and this justifies granting exemptions.

Exemptions from civil rights laws are often granted to certain groups, and especially to religious organisations, out of a respect for liberty of conscience and free exercise of religion-but also, more prudentially, to avoid potential social conflicts (Minow 2007, p. 782). Religious organisations have been exempt from regulations prohibiting gender and sexual orientation discrimination in the delivery of state funded social services, or in recruiting policies. In this case it is an organisation, rather than its individual members, that is granted exemption from universally applicable rules. Under US law, such exemptions are justified in the name of seeking a balance between the constitutionally guaranteed freedom of religious practice and 'compelling state interests' (Freeman 2002). Although not always explicitly stated, the need for some such trade-off has informed most of the discussion on rule and exemption in most Western countries.

Thus cases of rule and exemption, whether in theory or practice, are characterised by a suspension of strict legal equality in the name of some other value, such as the preservation of a cultural context for autonomous choices (Kymlicka 1995); equal opportunities (Parekh 2000), or equal respect or recognition (Modood 2007). The articles in this volume address key, difficult questions facing the proponents of any such approach.

First: how, and to what extent, can departures from universally applicable laws be justified? For many, it is definitive that-as Brian Barry (2001, pp. 32-40) has forcefully put it-if a law is just, then it must be applied universally without exception. Any law puts distinctive burdens on some citizens. Smokers are obviously more affected by smoking prohibitions than non-smokers, but as this follows from the very intention of the law, there seems to be nothing inherently wrong about it. If the law is justified insofar as it protects the legitimate interests of some citizens, then the fact that some other interests are penalised is simply part of what the law does: laws arbitrate among conflicting interests. Why should then practices and preferences linked to cultural identity be treated differently? Either a case for a general law cannot be made, or exemptions cannot be justified, except on purely practical grounds such as the avoidance of societal conflicts (for a debate see the articles in Kelly 2002). The articles by Emanuela Ceva and Enzo Rossi take issue with this problem and consider in which cases it might be possible to defend both a universal rule, and exemptions from it on the basis of religious or ethical beliefs and obligations. Ceva discusses whether liberal proceduralism about justice can make sense of forms of contestation of the law, such as conscientious objection and civil disobedience, based on specific substantial ethical and religious values endorsed by certain citizens. Rossi considers the question of whether, in 
circumstances of ethical pluralism, a procedure for the adjudication of rival claims based on the 'rule and exemption' approach is viable and legitimate. One important aspect of this discussion is whether we should treat the dispensations for minority groups as exemptions (which fall within previously established boundaries and admissible deviation from a rule) or exceptions, which seem to require ad hoc considerations.

A second issue concerning the rule and exemption approach arises from the fact that the demands of minority groups may either have an impact on the freedom of other groups or illiberal implications with regard to group members (Okin 1997). Supporters of moral and legal universalism regard exemptions as unacceptable insofar as they undermine the fundamental commitment to equality by conceding to some citizens certain liberties which are denied to others (Barry 2001; Kukathas 1992; Festenstein 2005). For example, it is difficult to justify why a religiously based claim should be accorded special treatment, whilst other particularistic claims are not granted the same consideration (Bedi 2007). As a result, in many circumstances is it hard to determine whether a cultural exemption enhances or impairs equal opportunities among citizens (Quong 2006). In their article, Elsa González, José Felix Lozano and Pedro Jesús Pérez, adopting a Habermasian perspective, argue that it is possible to defend exemptions for religious groups by drawing attention to a more positive understanding of religion than is generally offered by liberal theorists. Rather than considering strict equality before the law, they stress the role of churches and religious organisations as a source of values and motivation for citizens. They argue that some exemptions may be justifiable in order to support groups that positively contribute to maintaining and promoting a lively public sphere.

The rule and exemption approach has also been criticized insofar as it requires political institutions to identify individual citizens as members of well-defined religious or cultural groups (Galston 2004, pp. 66-69). At least prima facie exemptions seem to avoid problems arguably typical of multiculturalist policies. Although they often rely on a 'relational' and sometimes 'communitarian' understanding of the individual, for example, exemptions are not 'group rights', insofar they are granted to individuals as a liberty. However it seems that the definition of groups and ascription of membership for the sake of exemptions may lead to an oversimplified understanding of the complexity of individual identity and the very (often mixed) composition of groups themselves (see for example Fraser and Honneth 2003; Benhabib, 1996; Young 2000). Furthermore, the possible concession of religion-based rights to conscientious objection may entail judicial inquiry as to whether an individual citizen is a faithful member of a religious community and a sincere holder of certain beliefs, or whether the exemption is being requested opportunistically (Levy 1997, p. 28). All this, arguably, leads to the depiction of a rather intrusive role for the state, well beyond the circumscribed functions that have been traditionally assigned to it in liberal theories. Maria Paola Ferretti's article points to the relevance of focussing on the definition and re-definition of groups for the sake of granting and justifying exemptions, and defends an interest-based approach to such definitions. 
Individually and in sum, the articles in this special issue represent the beginning rather than the end of a research programme on the various instruments that may facilitate the hard task of reconciling respect for citizens' ethical and cultural allegiances with the ideal of universal citizenship and equal treatment. They are designed to offer an overview of the current discussion while at the same time offering original contributions to a scholarly debate that is just evolving.

Acknowledgments The contributions to this Special Issue draw on research carried out with the support of the Specific Targeted Research Project (STREP) EuroEthos: Exploring the Scope for a Shared European Pluralistic Ethos-A comparative investigation of religious and secular ethically-derived requests for exemption from the law in an enlarging Europe, funded under the European Commission's 6th Framework Programme (contract no. 028522).

\section{References}

Barry, Brian. 2001. Culture and equality. Cambridge: Polity Press.

Bedi, Sonu. 2007. What is so special about religion? The dilemma of the religious exemption. The Journal of Political Philosophy 15: 235-249.

Benhabib, Seyla (ed.). 1996. Democracy and difference: Contesting the boundaries of the political. Princeton: Princeton University Press.

Festenstein, Matthew. 2005. Negotiating diversity: Culture, deliberation, trust. Cambridge: Polity Press. Fraser, Nancy. 1989. Unruly practices: Power, discourse, and gender in contemporary social theory. Minneapolis: University of Minnesota Press.

Fraser, Nancy, and Axel Honneth. 2003. Redistribution or recognition? London and New York: Verso. Freeman, Samuel. 2002. Liberalism and the accommodation of group claims. In Multiculturalism reconsidered, ed. Paul Kelly, 18-30. Cambridge: Polity.

Galston, William. 2004. The practice of liberal pluralism. Cambridge: Cambridge University Press.

Kelly, Paul (ed.). 2002. Multiculturalism reconsidered: Culture and equality and its critics. Cambridge: Polity Press.

Kukathas, Chandran. 1992. Are there any cultural rights? Political Theory 20: 105-109.

Kymlicka, Will. 1995. Multicultural citizenship: A liberal theory of minority rights. Oxford: Oxford University Press.

Levy, Jacob T. 1997. Classifying cultural rights. In Ethnicity and group rights, eds. Ian Shapiro and Will Kymlicka, NOMOS XXXIX, 22-66. New York: New York University Press.

Minow, Martha. 2007. Should religious groups be exempt from civil rights laws? Boston College Law Review 48: 781-849.

Modood, Tariq. 2007. Multiculturalism: A civic idea. Cambridge: Polity Press.

Okin, Susan. 1997. Is multiculturalism bad for women? In eds. Joshua Cohen, Matthew Howard, and Martha C. Nussbaum. Princeton: Princeton University Press.

Pateman, Carole. 1988. The sexual contract. Cambridge: Polity Press.

Parekh, Bhikhu. 2000. Rethinking multiculturalism. Basingstoke: Palgrave.

Quong, Jonathan. 2006. Cultural exemptions, expensive tastes, and equal opportunities. Journal of Applied Philosophy 23 (1): 53-71.

Raz, Joseph. 1986. The morality of freedom. Oxford: Clarendon Press.

White, Stuart. 2007. Equality. Cambridge: Polity Press.

Young, Iris Marion. 1990. Justice and the politics of difference. Princeton: Princeton University Press. Young, Iris Marion. 2000. Inclusion and democracy. Oxford: Oxford University Press. 